\title{
Studi Perilaku Investor dan Myopic Loss Aversian
}

Jurnal Akuntansi Terapan Indonesia Vol 4 No $1 \mathrm{Hal} 70-78$ March 2021

\section{Affiliation:}

Universitas Negeri Malang, Indonesia

*Correspondence:

rizkiseptiani1997@gmail.com

This Article is Avalilable in:

https://journal.umy.ac.id/index. php/jati/article/view/9303

\section{DOI:}

https://doi.org/10.18196/jati.v4i1.930 3

\section{Citation:}

Septiani, R., Maharani, S., \& Ermayda, R. (2021). Studi Perilaku Investor dan Myopic Loss Aversian. Jati: Jurnal Akuntansi Terapan Indonesia, 4(1), 7078.

\section{Article History}

Received:

22 July 2020

Reviewed:

19 Agustus 2020

Revised:

27 Agustus 2020

Accepted:

01 February 2021

Topic Article:

Behavioral Accounting

\author{
Rizki Septiani ${ }^{* 1}$, Satia Nur Maharani ${ }^{2}$, Ria Zulkha Ermayda ${ }^{3}$
}

\begin{abstract}
:
An experienced investor's mindset tends to be different from that of a novice investor who has certain considerations heavily influenced by feelings and emotions. This mindset has unwittingly led to behavioral bias. One behavioral bias that often arises without being realized by investors, especially novice investors, is Myopic Loss Aversion (MLA). This study aimed to confirm the existence of Myopic Loss Aversion (MLA) behavioral bias and to analyze Myopic Loss Aversion (MLA) behavior bias inactive investors in Malang as well as the factors causing the emergence of Myopic Loss Aversion (MLA) behavior bias. This research was qualitative case study research. Primary data was obtained through in-depth interviews with selected informants. The results found that Myopic Loss Aversion arises in investors who conduct portfolio evaluations more frequently by monitoring fluctuating stock chart movements that seem to fear that their portfolio would suffer losses. Furthermore, another discovery was about how investors who had experienced Myopic Loss Aversion bias could overcome past mistakes in the investment decision-making process.
\end{abstract}

Keywords: Financial Behavior, Investors, Investment Decision Making

Abstrak:

Pola pikir investor yang sudah berpengalaman bisa berbeda dengan investor pemula yang cenderung masih memiliki pertimbangan tertentu yang banyak dipengaruhi oleh perasaan dan emosi. Pola pikir ini tanpa disadari telah memunculkan bias keperilakuan. Salah satu bias keperilakuan yang sering muncul tanpa disadari oleh investor terutama investor pemula yaitu Myopic Loss Aversian (MLA). Penelitian ini bertujuan untuk mengkonfirmasi eksistensi dari bias keperilakuan Myopic Loss Aversian (MLA) dan menganalisis bias perilaku Myopic Loss Aversian (MLA) pada investor aktif di Malang serta faktor penyebab munculnya bias perilaku Myopic Loss Aversian (MLA). Penelitian ini merupakan penelitian kualitatif studi kasus. Data primer dilakukan melalui wawancara mendalam terhadap informan terpilih. Hasil penelitian ini ditemukan bahwa Myopic Loss Aversian muncul pada investor yang melakukan evaluasi portofolio secara lebih frekuen melaui pemantauan pergerakan grafik harga saham fluktuatif yang seakan-akan takut portofolionya mengalami kerugian. Lebih lanjut, juga ditemukan tentang bagaimana para investor yang pernah mengalami bias Myopic Loss Aversian mengatasi kesalahan-kesalahan dimasa lalu dalam proses pengambilan keputusan investasi.

Kata Kunci: Perilaku Keuangan, Investor, Pengambilan Keputusan Investasi

\section{PENDAHULUAN}

Informasi terkait prospek saham atau portfolio dari perusahaan sangat perlu digali lebih dalam oleh calon investor. Informasi tersebut terdiri dari kinerja keuangan perusahaan, 
prospek perusahaan seperti ekspansi, hingga mengenai tanggung jawab manajemen kepada pemegang kepentingan yang lain (stakeholders). Bagi investor, informasi tersebut merupakan signal yang sangat berguna dalam pengambilan keputusan. Dengan demikian, investor dapat memprediksi bagaimana pergerakan harga saham nantinya. Namun terkadang terdapat reaksi yang berbeda-beda dari investor dalam memperlakukan informasi tersebut. Sebagai investor yang rasional tentunya investor akan memfokuskan diri menggunakan informasi tersebut untuk membantu memprediksi hasil atas dana yang diinvestasikan. Berbeda halnya dengan investor irasional, terkadang sisi psikologi juga berperan besar pada tindakan mereka dalam mengambil keputusan.

Puspitaningtyas (2013) mengungkapkan bahwa sisi psikologi mendorong investor untuk bertindak di luar kendali, seperti ketakutan (fear), keserakahan (greed), dan kepanikan (madness). Ketakutan tersebut menyebabkan investor cenderung menghindari kerugian yang besar. Dengan demikian, investor sejenis ini akan mencari portofolio yang dianggap aman dan berisiko kecil sehingga potensi kerugian sangatlah sedikit. Ketakutan ini bisa saja muncul dari pengalaman investor yang sebelumnya pernah gagal hingga rugi besar. Meskipun demikian, rasa takut terhadap kerugian dianggap wajar dalam berinvestasi saham, namun tidak wajar ketika rasa takut tersebut berlebihan hingga berpotensi menggagalkan tujuan di awal.

Berbanding terbalik dengan ketakutan (fear), keserakahan (greed) merupakan tindakan investor yang hanya berfokus untuk mencari keuntungan yang sebesar-besarnya hingga mengabaikan risiko investasi saham yang mengiringinya. Jika tidak hati-hati mengelola risiko tentunya akan menyebabkan kerugian yang besar bagi investasinya. Kemudian, kepanikan (madness) juga dapat dikatakan menjadi salah satu penyebab gagalnya rencana investasi terutama pada saat investor dihadapkan dengan kondisi anjloknya harga saham. Reaksi pertama yang muncul pasti panik dan dengan secepatnya berusaha menjual saham tersebut meskipun dengan harga rendah. Sebagaimana Tandelilin (2010) mengungkapkan bahwa dibalik potensi keuntungan yang tinggi terdapat potensi risiko yang tinggi pula.

Salah satu bias keperilakuan yang sering muncul tanpa disadari oleh investor terutama investor pemula yaitu MLA (Myopic Loss Aversian). MLA pertama kali diperkenalkan oleh Benartzi \& Thaler (1995) dimana MLA merupakan kombinasi dari loss aversion dan mental accounting. Loss Aversion menjelaskan tentang perilaku investor yang cenderung lebih sensitif terhadap kerugian dari pada keuntungan atas investasinya. Pada mental accounting, menjelaskan secara kognitif yang dilakukan suatu individu untuk mengatur, mengevaluasi, dan melacak aktivitas keuangan. Sebagai contoh, individu memiliki sikap/perlakuan yang berbeda terhadap kategori pengeluaran, seperti biaya hidup, biaya hiburan, dll (He \& Zhou, 2014). Investor dapat dikatakan menderita MLA apabila jenis portofolio yang dipilih adalah portofolio yang berisiko kecil ditambah dengan mengevaluasi portofolio yang dilakukan sesering mungkin atau terus menerus seakan-akan takut investasinya akan mengalami kerugian. Lee \& Veld-Merkoulova (2016) telah menunjukkan hasil survey terkait Myopic Loss Aversian (MLA) dan keputusan investasi dari masing-masing investor, yakni investor cenderung mengevaluasi kinerja portofolio saham terlalu sering, sehingga kecenderungan pada MLA. Efek miopia paling jelas terlihat ketika investor sering mengevaluasi portofolionya dan memperdagangkan saham secara teratur. Keseriusan dan kehati-hatian investor tentu harus didasari oleh pengambilan keputusan yang tepat mengingat setiap aktivitas terdapat sebuah risiko didalamnya.

Peneliti memilih investor aktif yang sudah bekerja dan berusia sekitar 23-29 tahun sebagai informan. Sejalan dengan Christanti \& Mahastanti (2011) dalam penelitiannya yang menunjukkan bahwa sebagian besar responden (investor) di Salatiga dan Semarang berusia 
25-29 tahun. Pada rentang usia tersebut investor berada di fase usia produktif dan fase pengembangan karir dan urusan keluarga, sehingga focus mereka adalah untuk bekerja dan menghasilkan uang sebanyak mungkin. Diperkuat dengan Rützler, Sutter, \& Zeileis, (2015) yang membuktikan bahwa perilaku MLA tidak tampak dalam sampelnya sebanyak 755 remaja yang berusia $11-18$ tahun.

Penelitian ini bertujuan untuk mengkonfirmasi esksistensi dari bias keperilakuan MLA dan menganalisis bias perilaku MLA pada investor aktif di Malang. Lebih lanjut, penelitian ini juga menganalisis faktor penyebab munculnya bias perilaku MLA pada diri investor yang mempengaruhi dalam pengambilan keputusan investasi sahamnya.

\section{METODE PENELITIAN}

Pendekatan yang digunakan dalam penelitian ini adalah pendekatan kualitatif. Peneliti menggunakan pendekatan kualitatif agar dapat memahami dunia makna subjek penelitian secara mendalam dimana dalam penelitian ini, peneliti menginginkan pemahaman yang lebih mendalam mengenai keeksistensian bias keperilakuan MLA pada investor aktif di Malang. Sedangkan jenis penelitian yang digunakan dalam penelitian ini adalah jenis penelitian studi kasus. Penelitian ini akan mengekplorasi informasi terkait bias perilaku MLA. Lebih lanjut, akan menjelaskan proses terbentuknya bias keperilakuan MLA yang terjadi pada investor aktif di Malang dalam pengambilan keputusan investasi. Malang dinilai memiliki galeri investasi dan komunitas investor dengan berbagai kalangan, mulai dari pelajar dan pekerja. Oleh karena itu, Malang menjadi lokasi penelitian yang menarik dalam penelitian ini.

Dalam penelitian ini, peneliti memilih investor aktif yang sudah bekerja sebagai subjek penelitian. Peneliti memilih investor aktif karena investor aktif memiliki intensitas bertransaksi (trading) secara berkala yang berpeluang besar terpengaruh kondisi psikologi dalam pengambilan keputusan investasinya. Peneliti juga memilih investor aktif yang sudah bekerja berusia sekitar 23-29 tahun. Usia tersebut dikategorikan sebagai masa adulthood dimana masa-masa ini merupakan masa dewasa awal yang usianya diawali 18 tahun ke 25 tahun hingga berakhir saat seseorang berusia 40 tahun (Hurlock, 1990).

Data yang digunakan dalam penelitian ini adalah data primer dan sekunder. Data primer dalam penelitian ini diperoleh dari hasil wawancara tidak terstruktur terhadap 3 informan terpilih,yaitu RZ dan AN seorang karyawan swasta, serta RA yang merupakan karyawan swasta sekaligus Ibu Rumah Tangga. Data sekunder diperoleh dari studi literatur buku, penelitian terdahulu serta sumber lain yang berkaitan dengan penelitian.

\section{HASIL DAN PEMBAHASAN}

\section{Investasi Saham: Sebuah Upaya Menyeimbangkan Kebutuhan Materi Investor}

Investasi saham dinilai sebagai langkah yang tepat untuk mempersiapkan dana di masa mendatang dan dipandang sebagai senjata yang ampuh untuk memenuhi berbagai keperluan. Hal tersebut sesuai dengan jawaban yang peneliti peroleh dari para informan melalui wawancara secara mendalam. Seperti yang telah diungkapkan oleh RZ (Informan) berikut ini yang menyatakan bahwa alasan mengikuti kegiatan investasi adalah untuk menambah pemasukan.

"Dulu pas kuliah terbatas ya mbak soalnya kan dari orang tua. Belum kerja juga terus pas saya kenal saham ternyata investasi ke saham untungnya lumayan bisa nambah 
uang jajan. Dan sampai sekarang pun keuntungan yang saya dapat juga untuk kebutuhan sehari-hari. Dan saya lebih ke swing trader (jangka menengah) jadi ya kalo udah naik tinggal jual aja dan keuntungannya biasanya saya tarik dari rekening untuk keperluan apa gitu". (RZ)

\section{Sumber Dana Investor}

Dalam melakukan kegiatan investasi sudah pasti para pelaku investasi harus memiliki dana yang akan digunakan untuk berinvestasi. Mengingat dalam penelitian ini informan yang digunakan adalah investor aktif di Malang yang sudah bekerja, maka modal yang digunakan berasal dari penghasilan atau gaji yang diperoleh dari pekerjaan masing-masing. Para informan mengalokasikan beberapa persen dari gajinya untuk investasi saham dan sisanya dialokasikan untuk kebutuhan yang lain.

"Ya kalo dulu waktu kuliah dari orang tua, sekarang dari gaji. 20\% dari gaji". (RZ)

"Dulu waktu kuliah saya pakai uang saku dari orang tua mbak tak tabung gitu. Dulu saya pas pertama kali pakai modal 500 ribu. Setelah itu ya gak menentu tergantung saku dari orang tua. Kalo sekarang ya jelas dari gaji wong saya sudah kerja, 30 persen dari gaji saya tak sisihkan buat investasi saham". (AN)

"lya mbak dari gaji. Nyisihin 30\% dari gaji itu". (RA)

Berdasarkan informasi yang diperoleh dari informan menunjukkan bahwa ketersediaan dana berpengaruh terhadap nilai transaksi dalam investasi saham. Semakin banyak dana yang tersedia semakin banyak kesempatan untuk digunakan sebagai modal berinvestasi sehingga peluang keuntungan juga tinggi.

Informan AN dan RZ juga menjelaskan nilai transaksi saat ini (sudah bekerja) lebih besar daripada saat masih kuliah. Hal tersebut dikarenakan pada saat kuliah dana yang digunakan sangat terbatas tergantung pada pemberian orangtua. Sedangkan dengan status kerja, ada pemasukan rutin setiap bulannya sehingga transaksi yang dilakukan juga rutin dan berpeluang untung besar.

\section{Motivasi sebagai Penentu Perencanaan Keputusan Investasi Saham}

Apapun alasannya, setiap orang pasti memiliki motivasi yang mendasari keputusan investasi tersebut. Motivasi inilah yang mendasari minat seseorang untuk menarik diri ke dalam pasar modal, terutama saham. Adapun hasil penelitian yang menunjukan bahwa motivasi berpengaruh terhadap minat berinvesatasi pada wanita (Kusmawati, 2011). Tidak hanya wanita, hasil penelitian tersebut juga akan berlaku pula kepada gender laki-laki karena pada dasarnya laki-laki juga memiliki kebutuhan dan kepentingan yang sama dalam masalah keuangan. Keputusan untuk berinvestasi juga merupakan salah satu tindakan yang diambil untuk pemenuhan kebutuhan untuk mencapai apa yang mereka pikirkan, karena berkarir dibidang investasi juga memberikan harapan masa depan yang cerah (Sharpe, 2005).

Adapun dalam wawancara yang peneliti lakukan menunjukkan bahwa para informan, secara garis besar menyatakan kebutuhan finansial menjadi motivasi terbesar bagi mereka untuk menarik diri ke dalam investasi saham. Kondisi finansial yang lebih baik memang menjadi harapan bagi setiap orang. Hal tersebut sesuai dengan pernyataan (Tandelilin, 2010) dimana salah satu alasan utama individu berinvestasi adalah untuk mendapatkan kehidupan yang layak di masa yang akan datang. Namun untuk mendapatkannya juga harus dibutuhkan pengorbanan dan kerja keras karena pada dasarnya investasi berarti mengorbankan dollar sekarang untuk dollar masa depan (Sharpe, 2005). 


\section{Eksistensi Myopic Loss Aversian dalam Pengambilan Keputusan Investor Aktif di Malang}

Berdasarkan wawancara yang telah peneliti lakukan, para informan menunjukkan sikap dan pengambilan keputusan yang berbeda-beda selama berinvestasi saham. Peneliti menyimpulkan terdapat beberapa tahap dalam proses pengambilan keputusan para informan selaku investor aktif. Tahap proses pengambilan keputusan tersebut mulai dari pemilihan jenis saham, pembelian saham, evaluasi portofolio, hingga pelepasan saham.

“... saham bluechip mbak soalnya dia punya fundamen yang bagus. Memiliki growth dan dikenal banyak orang bahkan liquid juga jadi gak bisa digoreng dalam artian aman lah". (AN)

"Kalo saya yang lq45 yang bluechip aja tapi dulu pernah gorengan pas kuliah. Karena kalo di gorengan itu apa ya, sedikit menjanjikan kan lah, kenaikannya kan signifikan ya tapi risikonya itu juga cukup tinggi karena bisa turun dalam juga". (RZ)

Haigh \& List (2005) menyatakan bahwa seseorang dikatakan menderita loss aversion apabila keberhati-hatiannya lebih berfokus pada kerugian (losses) daripada keuntungan (gains). Hal ini berarti seorang investor yang memiliki kecenderungan memiliki bias loss aversion akan memposisikan dirinya untuk mengambil keputusan investasi pada portofolio yang dianggap aman dan memiliki realisasi kerugian yang kecil. Pada penelitian telah menunjukkan hasil bahwa terdapat informan yang memiliki kecenderungan pola perilaku bias Myopic Loss Aversian (MLA). Hal ini terlihat dari cara mereka untuk memilih instrumen investasi yang lebih aman, yaitu ketika RZ dan AN mengalihkan dana mereka ke reksadana akibat trauma pernah gagal (rugi).

"Ya itu memang saya ngalamin rugi yang gede sih mbak. Ditambah lagi dana yang saya pakai saat itu terbatas. Udah capek-capek nabung nyisihin biar gak jajan eh ternyata hilang begitu aja. Ya trauma waktu itu. Sampek setelah itu saya berhenti transaksi terus sisa dananya tak pindahkan ke reksadana semuanya. Maksudku biar aman karena reksadana risikonya memang lebih kecil dari saham". (RZ)

"Yang namanya pemula kurang percaya sama fundamental. Keburu sama emosi. Waktu itu memang turun harganya, kan awalnya saya percaya kalo saham ini fundamentalnya bagus, walaupun begitu pastinya ada naik turunnya harga. Dan ternyata itu memang terjadi pas lihat grafik, harganya turun, saya disitu panik terus langsung tak jual rugi. Pernah rugi besar mbak sekitar satu juta. Dulu itu trauma mbak. Uang sejuta kalo untuk mahasiswa sudah gede itu. Pastinya kecewa dan menyesal bahkan saat itu saya inisiatif buat memindahkan sisa dananya ke reksadana sambil mengevaluasi kesalahan saya terletak dimananya". (AN)

Sedangkan, Informan Ria juga menunjukkan bahwa ketakutan mengalami rugi karena pengaruh oleh teman sebayanya. Hal ini berkaitan dengan pernyataan yang diungkapkan Zhang, Liu, Chen, \& Shang (2017) yang mengungkapkan bahwa pengaruh dari teman sebaya rentan untuk memunculkan perilaku loss aversion dalam pengambilan keputusan investasi. Hal tersebut disebabkan oleh adanya kesamaan emosi yang secara tidak langsung dirasakan ketika salah satu pihak mengalami kerugian. Tidak hanya teman sebaya, Ria juga mengaku ada ketergantungan atas rekomendasi dari sekuritasnya selama bertransaksi saham yang dirasa lebih mampu dan akurat.

Nunggu saran dari review harian sekuritas, mereka setiap hari update pas pembukaan pasar. Ya aku sih masih gunain feeling sama rekomendasi dari sekuritas. Terkadang juga 
dari teman-teman di grup sosmed gitu terus berita-berita di harian dikontan yang dibagikan sama teman-teman di grup itu". (RA)

\section{Faktor-faktor Terbentuknya Bias Myopic Loss Aversian pada Investor Aktif di Malang}

Berdasarkan penelitian ini, ditemukan beberapa faktor terbentuknya bias Myopic Loss Aversian dalam diri investor aktif di Malang. Faktor-faktor tersebut adalah sebagai berikut.

\section{Pengetahuan dan Pengalaman}

Pengetahuan dasar mengenai investasi merupakan hal sangat penting untuk diketahui oleh calon investor. Ukuran variabel yang digunakan untuk pengetahuan investasi adalah pemahaman tentang kondisi berinvestasi, pengetahuan dasar penilaian saham, tingkat risiko dan tingkat pengembalian (return) investasi (Kusmawati, 2011).

Pengalaman dalam penelitian ini adalah seberapa lama investor telah melakukan investasi pada pasar modal. Chou, Huang, Liang, \& Hsu, Hui (2010) membuktikan bahwa ada perbedaaan signifikan risk perception antara investor yang berpengalaman lebih dengan yang kurang berpengalaman. Kurangnya pengetahuan dan pengalaman membuat para informan mengambil keputusan secara impulsive tanpa pertimbangan lebih matang.

“... pernah beli sahamnya Bumi Resource kode sahamnya BUMI. Setelah beli harganya semakin lama semakin turun dan drastis terus kena suspend. Waktu itu gak lihat laporan keu (fundamental) karena masih pemula banget. Ya itu pengalaman berharga juga sih". (RZ)

\section{Sikap Gegabah}

Perilaku Myopic Loss Aversian didasari oleh rasa panik yang muncul ketika melihat pergerakan saham yang sangat fluktuatif. Pada saat itu, informasi mengenai harga saham tersebut tidak benar-benar dicerna didalam otak tetapi mereka langsung mengambil keputusan bahwa saham tersebut layak untuk dibeli tanpa melihat analisis fundamental maupun teknikal (Ramdani, 2018). Utami (2015) mengatakan bahwa investor yang memiliki sikap gegabah dikategorikan sebagai investor naif. Investor naif adalah investor yang melakukan transaksi saham tanpa memiliki ilmunya, tanpa mempertimbangkan analisis, dan tanpa mempertimbangkan return dengan baik, dan hanya memiliki pengetahuan yang minim serta hanya melihat pergerakan harga dari chart.

"Dan ternyata itu memang terjadi pas lihat grafik, harganya turun, saya disitu panik terus langsung tak jual rugi. Pernah rugi besar mbak sekitar satu juta". (AN)

\section{Sentimen Pasar}

Pada saham short term sentimen pasar akan lebih sering terjadi dan terkadang sulit untuk diprediksi. Hal ini pula yang menjadi salah satu pemicu munculnya Myopic Loss Aversian pada informan selaku investor aktif di Malang. Hal itu terbukti dari aksi Rizal yang selalu merasa panik (takut rugi) akibat selalu memantau pergerakan harga saham gorengan (saham short term) miliknya yang bergerak secara fluktuatif.

\section{Cara Investor Mengatasi Bias Myopic Loss Aversian untuk Meminimalisir Kesalahan dalam Pengambilan Keputusan Investasi}

Pada penelitian ini, para informan telah belajar dari kesalahan untuk mengatasi biastersebut. Cara mengatasinya adalah sebagai berikut.

$$
\text { Jati : Jurnal Akuntansi Terapan Indonesia, } 2021 \text { | } 75
$$




\section{Kemampuan Menganilisis}

Melalui analisa dengan benar, para investor akan semakin jarang terkena bias Myopic Loss Aversian. Hal ini terbukti dari aksi Rizal dan Anton yang selalu belajar lagi setelah mengalami trauma akibat kerugian yang diderita mereka. Mereka belajar lagi dengan mengikuti seminar-seminar yang ada dikampusnya bahkan diluar kampus. Setelah dirasa pengetahuan yang dimilikinya cukup, mereka percaya diri kembali dan memutuskan kembali ke investasi saham.

\section{Membuat Setting Goals}

Dalam penelitian ini, setting goals yang dibuat informan adalah menentukan batas persentase untuk taking profit dan cutloss. Ketika persentase penurunan atau kenaikan harga telah melewati batasnya maka mereka akan segera melakukan tindakan berupa taking profit maupun cutloss tersebut. Dengan memiliki setting goals, investor tidak perlu merasa khawatir dan panik pada saat pasar dalam keadaan bearish atau terjadi penurunan secara keseluruhan, karena pada dasarnya asalkan fundamental saham yang dibelinya bagus, harga akan kembali normal.

"Setting goals itu kayak jadi sebuah komitmen biar saya lebih terkendali pas trading mbak. Jadi ya biar gak grusa-grusu gitu biar kesabarannya terlatih juga". (AN)

\section{Tidak Menggunakan Uang Panas atau Darurat sebagai Modal Investasi}

Modal investasi merupakan hal utama yang diperlukan untuk berinvestasi saham. Sumber modal tersebut pun perlu diperhatikan. Hal ini telah diungkapkan oleh informan Rizal dimana penggunaan uang darurat, misal dari hutang, memberikan pengaruh besar pada perilaku investor, dimana dengan penggunaan uang darurat investor akan merasa tertekan dan selalu khawatir (panik), bahkan gegabah ketika mengambil keputusan. Sedangkan dengan uang yang benar-benar tidak terpakai akan menyelamatkan investor dari kerugian yang tidak terduga.

“... terus itu modal yang digunakan jangan uang panas dalam artian uang dari hutang misalnya. Lebih baik gunakan uang dingin yang benar-benar tidak terpakai atau memang tujuannya dialokasikan untuk investasi. Dulu saya pakai uang untuk biaya kuliah, dulu saya pikir uang saya akan meningkat ternyata karna pakai uang darurat itu saya was-was terus pas harganya turun". (RZ)

\section{KESIMPULAN}

Hasil penelitian ini ditemukan bahwa Myopic Loss Aversian muncul pada investor yang melakukan evaluasi portofolio secara lebih frekuen melalui pemantauan pergerakan grafik harga saham fluktuatif yang seakan-akan takut portofolionya mengalami kerugian. Ditemukan pula aspek-aspek yang mendasari munculnya Myopic Loss Aversian. Pertama, kurangnya pengetahuan dan pengalaman. Kedua, sikap gegabah. Investor yang mengambil keputusan secara gegabah akan lebih sering mengalami kerugian. Hal ini dikarenakan investor tidak melakukan perhitungan dengan matang yaitu mengambil keputusan yang didasari perasaan panik, tidak cermat dalam melakukan analisis, dan mengambil keputusan secara impulsive. Ketiga, sentimen pasar. Sentimen pasar ini berupa pergerakan harga yang fluktuatif secara terus menerus dan sulit untuk diprediksi. 
Penelitian ini juga menemukan tentang bagaimana para investor yang pernah mengalami bias Myopic Loss Aversian mengatasi kesalahan-kesalahan dimasa lalu dalam proses pengambilan keputusan investasi. Pertama, meningkatkan kemampuan analisis, yang didasari dengan pengetahuan dan pengalaman yang mereka miliki, bukannya hanya berdasarkan feeling dan spekulasi semata. Analasis juga sebaiknya dilakukan secara mandiri, karena apabila analisisis dilakukan dengan cara bergantung kepada pihak lain keadaan emosionalnya relatif labil. Kedua, yaitu membuat setting goals. Setting goals sangat berguna sebagai pengendali diri (self control) agar terhindar dari keengganan mengambil risiko maupun sifat serakah. Setting goals ini berguna agar investor selalu disiplin terhadap rencana keputusan diawal ketika pasar dalam keadaan chaos, baik pada saat kondisi bullish maupun bearish. Terakhir, tidak menggunakan uang panas, agar tidak tertekan dan khawatir saat bertransaksi sehingga mengurangi pemicu munculnya rasa takut (Myopic Loss Aversian). Penelitian selanjutnya dapat dilakukan dengan mengkaji MLA dengan skala yang lebih luas dan mengkaji bias keuangan keperilakuan yang lainnya.

\section{DAFTAR PUSTAKA}

Benartzi, S., \& Thaler, R. H. (1995). Myopic Loss Aversion and the Equity Premium Puzzle. The Quarterly Journal of Economics, 110, 73-92.

Chou, S. R., Huang, Liang, G., \& Hsu, Hui, L. (2010). Investor Attitude and Behavior towards Inherent Risk and Potential Return in Financial Products. International Research Jornal of Finance and Economics, 44, 16-29.

Christanti, N., \& Mahastanti, L. A. (2011). Faktor-Faktor Yang Dipertimbangkan Investor Dalam Melakukan Investasi. Jurnal Manajemen Teori Dan Terapan | Tahun, 4(3), 37-51.

Haigh, M. S., \& List, J. . (2005). Do Professional Traders Exhibit Myopic Loss Aversion? An Experimental Analysis. The Journal of Finance, 60, n, 523-534.

He, X. D., \& Zhou, X. Y. (2014). Myopic loss aversion, reference point, and money illusion. Quantitative Finance, 14(9), 1541-1554. https://doi.org/10.1080/14697688.2014.917805

Hurlock, E. . (1990). Psikologi Perkembangan: Suatu Pendekatan Sepanjang Rentang Kehidupan (Alih Bahas). Jakarta: Erlangga.

Kusmawati. (2011). Pengaruh Motivasi Terhadap Minat Berinvestasi Di Pasar Modal Dengan Pemahaman Investasi Dan Usia Sebagai Variabel Moderat. Jurnal Ekonomi Dan Informasi Akuntansi (Jenius), Vol. 1, no.

Lee, B., \& Veld-Merkoulova, Y. (2016). Myopic loss aversion and stock investments: An empirical study of private investors. Journal of Banking and Finance, 70, 235-246. https://doi.org/10.1016/j.jbankfin.2016.04.008

Puspitaningtyas, Z. (2013). Perilaku Investor dalam Pengambilan Keputusan Investasi di Pasar Modal. Conference Paper. Universitas Negeri Jember.

Ramdani, F. N. (2018). Analisis Pengaruh Representativeness Bias dan Herding Behavior terhadap Keputusan Investasi (Studi pada Mahasiswa di Yogyakarta). Fakultas Ekonomi Universitas Islam Indonesia.

Rützler, D. G., Sutter, M., \& Zeileis, A. (2015). No myopic loss aversion in adolescents? - An experimental note. Journal of Economic Behavior and Organization, 111, 169-176. https://doi.org/10.1016/j.jebo.2014.12.021

Sharpe, W. . (2005). Investasi. Jakarta: PT. Indeks Kelompok Gramedia.

Tandelilin, E. (2010). Portofolio dan Investasi Teori dan Aplikasi (Edisi Pert). Yogyakarta: Kanisius.

Utami, S. (2015). Manajemen Psikologi dalam Investasi Saham, Kajian Fenomenologi dalam Sentuhan Behavioral Finance. Yogyakarta: CV. Andi Offset. 
Zhang, X., Liu, Y., Chen, X., \& Shang, X. (2017). Decisions for Others Are Less Risk-Averse in the Gain Frame and Less Risk-Seeking in the Loss Frame Than Decisions for the Self. Front Psychol. 